\title{
Conservative management of a self-fashioned de- functioning colostomy in a patient with complex psychiatric comorbidities
}

\author{
Thomas J Turner, ${ }^{1,2}$ Anthony W Lambert ${ }^{2,3}$
}

${ }^{1}$ Department of Medicine and Health, University of Manchester Faculty of Biology, Manchester, UK

${ }^{2}$ Department of General Surgery, Plymouth Hospitals NHS Trust, Plymouth, Devon, UK ${ }^{3}$ Defence Medical Group South West, Plymouth, Devon, UK

\section{Correspondence to}

Thomas I Turner,

thomasjaketurner@gmail.com

Accepted 25 September 2018

\section{DESCRIPTION}

A 53-year-old woman with a complex psychiatric history, including borderline personality disorder and post-traumatic stress disorder, presented to the emergency department with multiple incisions to her abdomen. Each was the result of self-harm with a razor blade. One full thickness laceration had incised the colon and consequently a section of large bowel had prolapsed, resulting in a self-fashioned stoma.

Since 2004, the patient had received ongoing input from local mental health services regarding her childhood sexual abuse, emotional instability and maladaptive coping mechanisms of increased alcohol use and self-harming. She had long identified with the idea of 'another part of her mind' that needed to be 'punished', and linked this to her childhood abuse. She was previously sectioned under the mental health act (MHA) for similar episodes of 'punishment' that had resulted in emergency laparotomies to repair visceral injuries

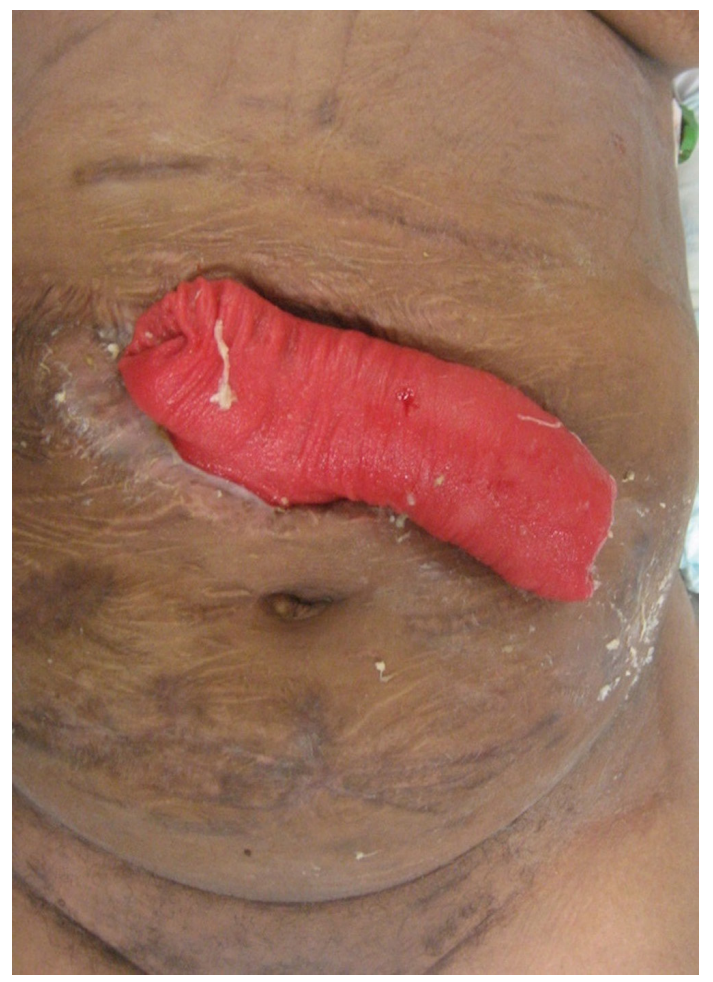

Figure 1 The anterior abdominal wall with multiple self-inflicted healed transverse lacerations and a mature, although prolapsed, self-fashioned colostomy.

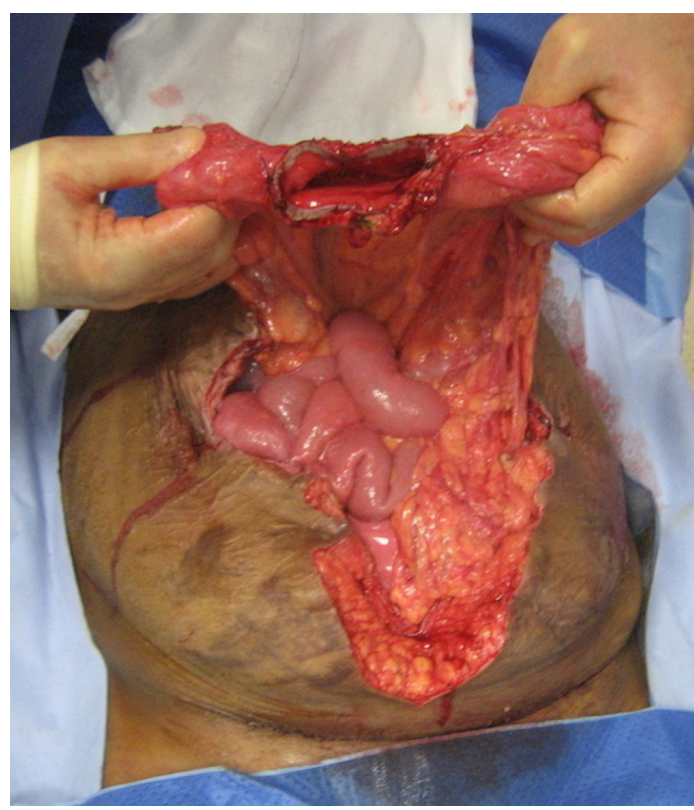

Figure 2 An elective midline laparotomy with closure of the self-fashioned colostomy and repair of the complex anterior abdominal wall hernias.

and formally close lacerations to her abdominal wall.

During this admission, the patient cut into her abdomen due to a strong desire to 'destroy' a part of herself that she described as weak, vulnerable and gullible, and was again sectioned under the MHA. However, on this occasion, there was considered to be a high risk of repeated self-harm and suicide. It was felt that if immediate surgical management was undertaken and there was a short-term recurrence of self-harm, the closure of the self-fashioned stoma may be threatened and her abdominal wall resultantly irreparable. It was therefore decided that the patient could initially be managed conservatively until surgical intervention could be considered an appropriate longterm measure in terms of her mental state. Her lacerations were dressed and input from stoma nurses was provided. This conservative management approach had the benefit of allowing the self-fashioned stoma to mature and become functioning, meaning that delaying formal repair was a feasible option while psychiatric treatment could be undertaken (figure 1).

The patient received inpatient psychological therapy using the 'Compassionate Mind Model' to 
help her reflect on her coping strategies. After 4 months, the patient was able to consent for closure of her colostomy and reconstruction of her anterior abdominal wall (figure 2).

Three years after surgery, she is living independently in her own home following a period of time in sheltered care, during which there have been no further episodes of self-harm. Although

\section{Patient's perspective}

"I was treated very well by my surgeon who fixed my exposed bowel. Even though I was not very happy having to wait for my operation, I now understand why my surgeon thought it was best to have my bowel fixed at a later date. Overall, I was very happy with the outcome and I felt I was kept very safe.'

\section{Learning points}

- The importance of effective communication within a multidisciplinary team in the surgical management of patients with complex psychiatric comorbidities.

- The need to balance the surgical and psychiatric management of a patient based on their individual needs, in order to optimise their return to the community with an improved long-term quality of life.

- The success of a conservative management approach to a hostile abdomen where appropriate in allowing the chronic needs of a patient to be addressed, in this case reducing the risks of recurrent self-harm and potentially irreparable injuries in a patient with concurrent psychiatric illness. thought to be an unconventional surgical approach, this holistic management of a patient with complex surgical and psychiatric pathology proved successful.

Self-harm is a cause of up to 200000 admissions to hospital each year in England, and concurrent psychiatric illness is a strong risk factor. ${ }^{1}$ Patients diagnosed with borderline personality disorder and post-traumatic stress disorder are associated with an increased risk of self-harm and suicide. ${ }^{2}$ Repetition of self-harm within the first year is reported to occur in approximately $16 \%$ of patients, with a higher risk of repetition seen in those with a greater number of psychiatric illnesses, including personality disorder. ${ }^{3}$ Therefore, early intervention of comorbid psychiatric illness in patients suffering self-harm injuries could reduce their recurrence, as illustrated in this case report.

Contributors Manuscript was written by TJT, with support from AWL on the writing of the report.

Funding The authors have not declared a specific grant for this research from any funding agency in the public, commercial or not-for-profit sectors.

Competing interests None declared.

Patient consent Obtained.

Provenance and peer review Not commissioned; externally peer reviewed.

\section{REFERENCES}

1 Singhal A, Ross J, Seminog O, et al. Risk of self-harm and suicide in people with specific psychiatric and physical disorders: comparisons between disorders using English national record linkage. J $R$ Soc Med 2014;107:194-204.

2 Mellesdal L, Gjestad R, Johnsen E, et al. Borderline Personality Disorder and Posttraumatic Stress Disorder at Psychiatric Discharge Predict General Hospital Admission for Self-Harm. J Trauma Stress 2015:28:556-62.

3 Larkin C, Di Blasi Z, Arensman E. Risk factors for repetition of self-harm: a systematic review of prospective hospital-based studies. PLoS One 2014;9(1).

Copyright 2018 BMJ Publishing Group. All rights reserved. For permission to reuse any of this content visit http://group.bmj.com/group/rights-licensing/permissions.

BMJ Case Report Fellows may re-use this article for personal use and teaching without any further permission.

Become a Fellow of BMJ Case Reports today and you can:

- Submit as many cases as you like

- Enjoy fast sympathetic peer review and rapid publication of accepted articles

- Access all the published articles

- Re-use any of the published material for personal use and teaching without further permission

For information on Institutional Fellowships contact consortiasales@bmjgroup.com

Visit casereports.bmj.com for more articles like this and to become a Fellow 